\title{
Hematopoietic stem cells as a tool for the treatment of glioblastoma multiforme
}

\author{
IGOR S. BRYUKHOVETSKIY ${ }^{1,2}$, INESSA V. DYUIZEN ${ }^{1,2}$, VALERIY E. SHEVCHENKO ${ }^{1,3}$, \\ ANDREY S. BRYUKHOVETSKIY ${ }^{1,4}$, POLINA V. MISCHENKO ${ }^{1,2}$, \\ ELENA V. MILKINA ${ }^{1,2}$ and YURI S. KHOTIMCHENKO ${ }^{1,2}$
}

\author{
${ }^{1}$ Far Eastern Federal University, School of Biomedicine, Vladivostok 690091; ${ }^{2}$ A.V. Zhirmunsky Institute of Marine Biology, \\ Far Eastern Branch of The Russian Academy of Sciences, Laboratory of Pharmacology, Vladivostok 690059; \\ ${ }^{3}$ N. N. Blokhin Russian Cancer Research Center, Laboratory of Oncoproteomics, Moscow 115478; \\ ${ }^{4}$ NeuroVita Clinic of Interventional and Restorative Neurology and Therapy, Moscow 115478, Russia
}

Received May 15, 2016; Accepted July 29, 2016

DOI: $10.3892 / \mathrm{mmr} .2016 .5852$

\begin{abstract}
Glioblastoma multiforme is an aggressive malignant brain tumor with terminal consequences. A primary reason for its resistance to treatment is associated with cancer stem cells (CSCs), of which there are currently no effective ways to destroy. It remains unclear what cancer cells become a target of stem cell migration, what the role of this process is in oncogenesis and what stem cell lines should be used in developing antitumor technologies. Using modern post-genome technologies, the present study investigated the migration of human stem cells to cancer cells in vitro, the comparative study of cell proteomes of certain stem cells (including CSCs) was conducted and stem cell migration in vivo was examined. Of all glioblastoma cells, CSCs have the stability to attract normal stem cells. Critical differences in cell proteomes allow the consideration of hematopoietic stem cells (HSCs) as an instrument for interaction with glioblastoma CSCs. Following injection into the bloodstream of animals with glioblastoma, the majority of HSCs migrated to the tumor-containing brain hemisphere and penetrated the tumor tissue. HSCs therefore are of potential use in the development of methods to target CSCs.
\end{abstract}

\section{Introduction}

Glioblastoma multiforme is an aggressive malignant brain tumor. Patient prognosis is poor, with a median survival of 6-12 months, as the standard treatment is ineffective.

Correspondence to: Dr Igor S. Bryukhovetskiy, Far Eastern Federal University, School of Biomedicine, 8 Sukhanova St., Vladivostok 690091, Russia

E-mail: igbryukhovetskiy@gmail.com

Key words: stem cells, neural stem cells, hematopoietic stem cells, cancer stem cells, glioblastoma multiforme, proteome mapping, migration
A primary cause of this resistance to treatment is the stem cells of the cancer cell population, which have unique signaling and morphogenetic properties (1-3).

Cancer stem cells (CSCs) represent a specific group of tumor cells that have maximum independence from external signals. Relatively small numbers of these cells are sufficient for the rapid activation of invasive growth and metastasis. These cells are multipotent, capable of constant self-renewal and have the greatest proliferative activity of all glioblastoma cells $(4,5)$. Specific features of CSCs include a hypoxic metabolism and an ability to restore damaged DNA $(6,7)$.

Previously, CSCs were considered to develop from differentiated cells. However, normal stem cells are now being viewed as the primary source of CSCs. The modern concept of carcinogenesis defines cancer and other malignant tumors as a genetic disease developing in the nucleus of a normal stem cell that renders its descendants (CSCs) unrecognizable to the immune system and, thus, safe from elimination (8). The eradication of CSCs is therefore crucial for cancer treatment; however, currently there are no effective methods to do this.

One approach to solving this problem is to develop chemotherapeutic agents that would seek out and destroy these cells. However, CSCs are a heterogeneous cell population and may adapt to sublethal exposure by producing new clones with greater resistance. It has been suggested that CSCs represent a specific survival mechanism of eukaryotic cells and are the result of a constant struggle for existence (9-11). Destruction of this target requires a highly accurate and powerful tool that exceeds the ability of CSCs to adapt.

Patient stem cells may potentially be this tool. The ability of stem cells (SCs) to migrate to the tumor node and interact with cancer cells has been proven $(12,13)$. Certain treatment strategies, including targeted drug delivery (14) and metallic nanoparticles for drug delivery (15), are based on the migration potential of SCs. In addition, SCs that secretes specific antibodies within the tumor have been demonstrated to improve survival in a mouse model (16). However, these strategies do not target the CSCs themselves. This is due to a lack of knowledge regarding which cancer cells become the target of stem cell migration, the role of this phenomenon in carcinogenesis 
and what stem cell lines should be used to develop antitumor cell therapy. The answers to these questions will define the direction of future investigations.

The aim of the present study was to evaluate the ability of glioblastoma cells to attract various tissue-specific human stem cells, and to compare normal and cancer stem cells.

\section{Materials and methods}

Cell culture. The U251 human glioblastoma cell line (cat. no. 09063001; Sigma-Aldrich; Merck Millipore, Darmstadt, Germany), the U87 human glioblastoma cell line (ATCC no. HTB-14 ${ }^{\mathrm{TM}}$; ATCC, Manassas, VA, USA), the MCF7 human breast cancer cell line (ATCC no. HTB-22 $2^{\mathrm{TM}}$ ), the A549 human lung cancer cell line (ATCC no.CCL-185 ${ }^{\mathrm{TM}}$ ), human fibroblasts (ATCC no. PCS-420-013 ${ }^{\mathrm{TM}}$ ) and the C6 rat glioma cell line (ATCC no. CCL-10 ${ }^{\mathrm{TM}}$ ) were employed for the purposes of the present study.

Cell lines were cultured at $37^{\circ} \mathrm{C}$ with $5 \% \mathrm{CO}_{2}$ in Dulbecco's modified Eagle's medium (DMEM; cat. no. 61965-026) containing $10 \%$ fetal bovine serum (FBS; cat. no. 1347559) and 100X Antibiotic-Antimycotic (cat. no. 160175; all from Gibco; Thermo Fisher Scientific, Inc., Waltham, MA, USA). The culture medium was changed every $72 \mathrm{~h}$. The cells for the experiment were treated with TrypLE Express according to the manufacturer's instructions (cat. no. 1606073; Gibco; Thermo Fisher Scientific, Inc.) for $7 \mathrm{~min}$ at $37^{\circ} \mathrm{C}$ and centrifuged for $3 \mathrm{~min}$ at $120 \mathrm{xg}$ at $20^{\circ} \mathrm{C}$. The supernatant was subsequently removed and fresh DMEM was added. The cells were counted in a hemocytometer, following staining with $0.4 \%$ trypan blue (cat. no. 15250061; Gibco; Thermo Fisher Scientific, Inc.) to assess viability.

To extract CSCs from U87 and U251 human glioblastoma cell lines, the cells were suspended in dispase/collagenase solution (dispase, $0.8 \mathrm{U} / \mathrm{ml}$; collagenase, $0.1 \mathrm{U} / \mathrm{ml}$; Roche Applied Science, Penzberg, Germany) in phosphate-buffered saline (PBS) for $1 \mathrm{~h}$ at $37^{\circ} \mathrm{C}$. Enzymatic reactions were inactivated in PBS $+5 \%$ FBS and the cells were centrifuged for $5 \mathrm{~min}$ at $800 \mathrm{x} \mathrm{g}$ at $20^{\circ} \mathrm{C}$. Cells were resuspended in DMEM/F-12 (cat. no. 12634-010; Gibco; Thermo Fisher Scientific, Inc.) containing L-glutamine, $20 \mathrm{ml} / 1 \mathrm{~B}-27$ supplement (cat. no. 17504044; Gibco; Thermo Fisher Scientific, Inc.), $20 \mathrm{ng} / \mathrm{ml}$ fibroblast growth factor $\beta$ (FGF- $\beta$; cat. no. PHG0023; Gibco; Thermo Fisher Scientific, Inc.), $20 \mathrm{ng} / \mathrm{ml}$ epidermal growth factor (EGF; cat. no. PHG0311; Gibco; Thermo Fisher Scientific, Inc.), 100 U/ml penicillin/streptomycin and $5 \mu \mathrm{g} / \mathrm{ml}$ heparin. Cells were cultured in T75 flasks at $37^{\circ} \mathrm{C}$ with $5 \% \mathrm{CO}_{2}$. Fresh growth factors were added every $72 \mathrm{~h}$. Adherent cells were cultured until $80 \%$ confluence was reached, before they were subcultured at a $1: 3$ ratio. Cluster of differentiation (CD) $133^{+}$cells were selected via magnetic-activated cell sorting (MACS) using an autoMACS Pro ${ }^{\circledR}$ and magnetic beads bound to immobilized CD133 antibodies (MiltenyiBiotec, Inc., San Diego, CA, USA), according to the manufacturer's instructions. The purity was assessed using a flow cytometer (BD Accuri C6; BD Biosciences, Franklin Lakes, NJ, USA).

Human neural stem cells (NSCs) derived from the olfactory epithelium of the superior turbinate were supplied by the NeuroVita Clinic of Interventional and Restorative Neurology and Therapy (Moscow, Russia). NSCs were treated with dispase/collagenase solution and resuspended in growth factor-containing DMEM/F-12 as described above. Cells were cultured until cytospheres formed and were then characterized by the expression of nestin (cat. no. ab22035; Abcam, Cambridge, MA, USA), Thy1 (CD90; cat. no. ab133350; Abcam); neurofilament 200 (NF200; cat. no. ab134306; Abcam) and glial fibrillary acidic protein (GFAP; cat. no. ab7260; Abcam) according to the manufacturer's recommendations. Cells were fixed with $4 \%$ paraformaldehyde (Sigma-Aldrich; Merck Millipore), washed with PBS, and incubated overnight at $4^{\circ} \mathrm{C}$ with $1-5 \mu \mathrm{g} / \mathrm{ml}$ primary antibodies. The cells were washed in PBS three times, and incubated for $1 \mathrm{~h}$ at $37^{\circ} \mathrm{C}$ with goat anti-mouseAlexaFluor633-conjugated IgG (cat. no. A-21146; Invitrogen; Thermo Fisher Scientific, Inc.) or goat anti-rabbit Alexa Fluor 488-conjugated $\operatorname{IgG}$ (cat. no. A-11008; Invitrogen; Thermo Fisher Scientific, Inc.) secondary antibodies at a concentration of $5 \mu \mathrm{g} / \mathrm{ml}$. The cell nuclei were then stained with DAPI (Sigma-Aldrich; Merck Millipore) before the cells were placed in 50\% glycerin (Sigma-Aldrich; Merck Millipore) and covered with a $0.17-\mathrm{mm}$ cover glass (Menzel-Gläzer, Braunschweig, Germany). CD133+ NSCs were sorted by MACS using an AutoMACS Pro ${ }^{\circledR}$ Separator and magnetic beads bound to immobilized CD133 antibodies (MiltenyiBiotec, Inc.), according to the manufacturer's instructions. The purity was assessed using a flow cytometer (BD Accuri C6; BD Biosciences).

Multipotent hematopoietic stem cells (HSCs) were supplied by the NeuroVita Clinic of Interventional and Restorative Neurology and Therapy (Moscow, Russia). The cells were obtained from bone marrow using Pittenger's method (17). Cells was assessed by flow cytometry based on the presence or absence of the following surface antigens: $\mathrm{CD} 29^{+}$ (cat. no. 130-101-255), CD44+ (cat. no. 130110393), CD73+ (cat. no. 130103065), CD90 (cat. no. 130-097-930) and $\mathrm{CD}^{+}{ }^{+}$(cat. no. 130-098-142). The fluorescein isothiocyanate-conjugated antibodies (MiltenyiBiotec, Inc.) were added to the suspension of studied cells $\left(1 \times 10^{5}\right)$ in the concentration recommended by the manufacturer, incubated for $30 \mathrm{~min}$ at $37^{\circ} \mathrm{C}$ and analyzed using a flow cytofluorometer (MiltenyiBiotec, Inc.).

Fibroblasts were cultured in DMEM supplemented with $10 \%$ FBS, $10 \mathrm{ng} / \mathrm{ml}$ EGF, $10 \mathrm{ng} / \mathrm{ml}$ FGF- $\beta$ and $100 \mathrm{X}$ Antibiotic/Antimycotic, replenished every four days, until confluence reached $70 \%$. Cells were harvested using $0.25 \%$ trypsin solution for $5 \mathrm{~min}$ at $37^{\circ} \mathrm{C}$, and centrifuged at $120 \mathrm{xg}$ for $3 \mathrm{~min}$ at $20^{\circ} \mathrm{C}$. The cells were counted in a hemocytometer, following staining with $0.4 \%$ trypan blue to assess viability. Prior to being used in the experiment, the material underwent fluorescent staining using Cell Tracker Red ${ }^{\mathrm{TM}}$ CMTPX dye (cat. no. C34552; Molecular Probes; Thermo Fisher Scientific, Inc.) according to the manufacturer's instructions.

Rat HSCs were supplied by the NeuroVita Clinic of Interventional and Restorative Neurology and Therapy (Moscow, Russia).

In order to assess the migration of human stem cells towards malignant cancer cells in vitro, tumor cells $\left(0.5 \times 10^{4}\right)$ were seeded onto culture plate inserts (cat. no. 30012; SPL Life Sciences, Pocheon, Korea) in a 12-well plate (Fig. 1). NSCs, 
HSCs and fibroblasts were stained with the fluorescent Cell Tracker $^{\text {TM }}$ Red CMTPX Dye (Molecular Probes; Thermo Fisher Scientific, Inc.) according to the manufacturer's instructions, and added to the wells $\left(0.5 \times 10^{4}\right.$ cells/well $)$. The number of cells that migrated to the walls of culture plate inserts was evaluated using the monitoring system Cell IQ ${ }^{\circledR}$ (CM Technologies Oy, Tampere, Finland) following $120 \mathrm{~h}$ of co-culture.

Proteome mapping of stem cells. Glioblastoma CSCs consisting of U87 CD133+ NSCs and HSCs, were lysed using a Mammalian Cell Lysis kit (Sigma-Aldrich; Merck Millipore) according to the manufacturer's instructions. Briefly, cells were collected transferred to a conical test tube and centrifuged at $25^{\circ} \mathrm{C}$ for $5 \mathrm{~min}$ at $420 \times \mathrm{g}$. The supernatant was decanted and the cells were washed twice by resuspending the cell pellets in PBS and centrifuging at $420 \times g$ for $5 \mathrm{~min}$ at $25^{\circ} \mathrm{C}$. After decanting the supernatant, cells were resuspended in cell lysis buffer $\left(10^{6}-10^{7}\right.$ cells $/ \mathrm{ml}$ ) and incubated for $15 \mathrm{~min}$ on an orbital shaker. The cells were subsequently centrifuged at $12,000 \times \mathrm{g}$ for $10 \mathrm{~min}$ at $25^{\circ} \mathrm{C}$ to pellet the cellular debris. The protein-containing supernatant was removed and transferred to a fresh test tube. Samples that were used immediately were incubated on ice, while the remaining samples were stored at $-20^{\circ} \mathrm{C}$.

Purification from low-molecular weight components. The subsequent tumor cell lysates were purified from low-molecular components using Agilent 5K MWCO $4 \mathrm{ml}$ Spin Concentrators for Proteins (Agilent Technologies GmbH, Waldbronn, Germany). Samples were placed in a CentriVap vacuum concentrator (Labconco, Kansas City, MO, USA) and centrifuged at $2000 \times g$ at $60^{\circ} \mathrm{C}$ until $200 \mu \mathrm{l}$ of fluid remained. Water $(4 \mathrm{ml})$ was added and the samples were centrifuged again under the same conditions. The samples were then washed three times, leaving $200 \mu \mathrm{l}$ of the sample. The sample was washed from the concentrator twice using $200 \mu$ l water. The resultant $600 \mu \mathrm{l}$ sample was used for downstream experiments, and total protein was measured using a Bradford protein assay kit (Sigma-Aldrich; Merck Millipore) according to the manufacturer's instructions. The volume of lysate containing $300 \mu \mathrm{g}$ protein was calculated and dried at $60^{\circ} \mathrm{C}$ in a CentriVap vacuum evaporator.

Tryptic cleavage. Trypsinolysis was performed using $150 \mu \mathrm{l}$ protein samples. Dried lysates were added to $25 \mu 1$ 2,2,2-trifluoroethanol (TFE), $25 \mu 1 \mathrm{NH}_{4} \mathrm{HCO}_{3}(100 \mathrm{mM})$ diluted in water and $2 \mu \mathrm{l}$ fresh trichloroethylphosphate (TCEP; $50 \mathrm{mM}$ ) diluted in water. The reaction mixture was exposed for $1 \mathrm{~h}$ at $60^{\circ} \mathrm{C}$, and then cooled to $25^{\circ} \mathrm{C}$. A total of $1 \mu \mathrm{l}$ fresh aqueous iodoacetamide (IAA; $84 \mathrm{mM}$ ) was added to the sample, which was then exposed for $30 \mathrm{~min}$ at $25^{\circ} \mathrm{C}$. A total of $100 \mu \mathrm{NH}_{4} \mathrm{HCO}_{3}$ (100 mM) solution, $300 \mu \mathrm{l}$ water and trypsin solution in $1 \mathrm{mM}$ of $\mathrm{HCl}$ (trypsin concentration $100 \mathrm{ng} / \mu \mathrm{l}$, trypsin: protein ratio, 1:50 by weight) was subsequently added to the sample, which was then exposed for $18 \mathrm{~h}$ at $37^{\circ} \mathrm{C}$. The solution $(3 \mu \mathrm{l})$ was analyzed using an LTQOrbitrap XL mass spectrometer (Thermo Fisher Scientific, Inc.) for the completion of trypsinolysis as described below. Completion of trypsinolysis was determined by analyzing the tryptic peptide peaks and by calculating the area under the peaks at m/z 842.51 Da and
421.76 Da. When the reaction was completed, the content of the tube was dried at $60^{\circ} \mathrm{C}$ in the CentriVap.

Liquid chromatography (LC)-mass spectrometry (MS)/MS analysis using the LTQ Orbitrap XL. Peptides were analyzed using an LTQ Orbitrap XL instrument (Thermo Fisher Scientific, Inc.) with a NanoSpray ionization (NSI) ion source coupled to an Ultimate 3000 Dionex nanoflow LC system (Dionex, Sunnyvale, CA, USA). High mass resolution was used for peptide identification. The reverse phase-LC system consisted of a peptide Cap-Trap cartridge (Acclaim C18 Pepmap100; $500 \mu \mathrm{m} \times 5 \mathrm{~mm}$; grain size $5 \mu \mathrm{m}$; Dionex) and the Acclaim C18 PepMap100 column ( $75 \mu \mathrm{m}$ in diameter and $15 \mathrm{~cm}$ length; grain size, $3 \mu \mathrm{m}$; Dionex). The sample $(20 \mu \mathrm{l})$ was loaded onto the trap cartridge for $1 \mathrm{~min}$ in $99 \% \mathrm{H}_{2} \mathrm{O}, 1 \%$ acetonitrile (ACN) and $0.1 \%$ formic acid (FA) and then washed for 4 min with $0.05 \%$ solution of trifluoroacetic acid (TFA) in water. The sample was then equilibrated for 1 min with $99 \% \mathrm{H}_{2} \mathrm{O}, 1 \% \mathrm{ACN}$ and $0.1 \%$ FA at a flow rate of $20 \mu \mathrm{l} / \mathrm{min}$ for concentrating and desalting. Peptides were subsequently eluted over 170 min from the analytical column via the trap cartridge using a linear gradient of $100 \%$ mobile phase $\mathrm{A}\left(98 \% \mathrm{H}_{2} \mathrm{O}, 2 \% \mathrm{ACN}\right.$ and $0.1 \%$ FA) to $100 \%$ mobile phase $\mathrm{B}\left(20 \% \mathrm{H}_{2} \mathrm{O}, 80 \% \mathrm{ACN}\right.$ and $\left.0.08 \% \mathrm{FA}\right)$ at a flow-rate of $0.3 \mu \mathrm{l} / \mathrm{min}$ using the following gradient: $0 \%$ phase B for $6 \mathrm{~min}$; 0-50\% phase B for 114 min; 50-100\% phase B for $30 \mathrm{~min}$; hold at $100 \%$ phase $\mathrm{B}$ for $15 \mathrm{~min} ; 100-0 \%$ phase B in 5 min; hold at $0 \%$ phase $B$ for $15 \mathrm{~min}$.

The LTQ Orbitrap XL equipped with a NSI was used for the MS/MS experiment in the positive ion mode, and was operated in a data-dependent mode using Xcalibur 2.02 software (Thermo Fisher Scientific, Inc.). The mass spectrometer settings were as follows: Spray voltage, $1.7 \mathrm{kV}$; capillary voltage, $43 \mathrm{~V}$; tube-lens voltage, $165 \mathrm{~V}$; ion transfer capillary temperature, $200^{\circ} \mathrm{C} ; 1$ microscan for MS1 scans at 30,000 resolution [full width at half maximum (fwhm) at $400 \mathrm{~m} / \mathrm{z}$; microscans for MS2 at 7500 resolution (fwhm at $400 \mathrm{~m} / \mathrm{z}$ ); full MS mass range, $300-2000 \mathrm{~m} / \mathrm{z}$; and MS/MS mass range, $100-2000 \mathrm{~m} / \mathrm{z}$. In each duty cycle, the 12 most abundant precursor ions with $a \geq 2$ charge state, were sequentially isolated to a target value of 10,000 ions for fragmentation, using collision-induced dissociation in a linear trap at $35 \%$ normalized collision energy (enhanced scanning mode). The acquired ions were dynamically excluded for $60 \mathrm{sec}$. The automatic gain control for full MS and MS/MS was set to $1 \times 10^{6}$ and $5 \times 10^{4}$ ions, respectively. The maximum ion accumulation time was set to $700 \mathrm{~ms}$ for MS and $150 \mathrm{~ms}$ for MS/MS scans. Triplicate repeats were performed for each sample.

Data analysis. The Proteome Discoverer ${ }^{\mathrm{TM}}$ software version 1.0 (Thermo Fisher Scientific,Inc.) was used to identify proteins from mass spectrometry analysis. Proteins were searched for using the Mascot Server software version 2.3.02 (Matrix Science, Ltd., London, UK). Identified proteins were sorted the Mascot Server software according to the Multidimensional Protein Identification Technology score and revealed peptides where $\mathrm{P}<0.05$. The lists of the identified proteins together with the LC-MS data were uploaded to the Skyline software program (version 1.2.0.3303; skyline.gs.washington. edu/labkey/project/home/software/Skyline/begin.view) to obtain the peak area of peptides in each sample. The sum of 
the peak areas of all identified peptides in each sample was calculated and normalized to the overall area of all identified proteins in the sample.

Chemicals and reagents. HPLC gradient grade ACN was purchased from BDH Prolabo (VWR Chemicals, Radnor, PA, USA) and FA was purchased from Merck Millipore. Urea (ultra-pure for molecular biology), ammonium bicarbonate (ultra-pure), dithiothreitol (ultra-pure for molecular biology), IAA, TFE (Reagent Plus), acetic acid (HAc), protease inhibitor cocktail, mammalian cell lysis kit, phosphate buffered saline (PBS) and trypsin (modified, proteomics grade) were obtained from Sigma-Aldrich (Merck Millipore). $\mathrm{NH}_{4} \mathrm{HCO}_{3}$, (ultra-pure), TCEP and TFA (for protein sequence analysis) were purchased from Fluka (Sigma-Aldrich; Merck Millipore). $\mathrm{HCl}$ (purum) and $\mathrm{KCl}$ (purum) were obtained from Chimmed, Inc. (Moscow, Russia). Water used in this research was prepared using the Milli-Q system (Merck Millipore).

Animals. The migration activity of HSCs in animals with glioblastoma was evaluated. A total of 50 adult female Wistar rats (age, three months; weight, $<220 \mathrm{~g}$ ) from the vivarium of the AV Zhirmunsky Marine Biology Institute (Vladivostok, Russia) were used for the purposes of this study. The animals were kept and cared for in accordance with the standards of good laboratory practice. The animals were maintained at room temperature $\left(20^{\circ} \mathrm{C}\right.$; relative humidity, $\left.60 \%\right)$, with natural day and night cycles and with access to water and food ad libitum. The present study was approved by the Ethics Committee at the A.V. Zhirmunsky Institute of Marine Biology. The control group without treatment included 25 animals with implantation of glioma C6 cells into the brain. Rats in the treatment group $(n=25)$ underwent a stereotactic implantation of C6 glioblastoma cells into the brain. Rats were examined by magnetic resonance imaging (MRI; Bruker BioSpec Pharma Scan 7T; Bruker Corporation, Billerica, MA, USA) at different stages to determine the presence of tumors, before 5 rats from each group were subject to histological analysis on days 7, 14, 21 and 28.

Implantation of rat glioma cells. C6 rat glioma cells were cultured as described above, and analyzed by immunofluorescence. Cells were fixed in $4 \%$ paraformaldehyde (PFA), washed in $0.1 \mathrm{M}$ PBS (pH 7.4) with $0.2 \%$ Tween 20 and $0.2 \%$ TritonX-100 (Sigma-Aldrich; Merck Millipore) and nonspecific binding was blocked with $0.3 \%$ bovine serum albumin (cat. no. B4287-25G; Sigma-Aldrich; Merck Millipore). Cells were incubated with the following primary antibodies for $24 \mathrm{~h}$ at $4^{\circ} \mathrm{C}$ : Mouse anti-p53 (1:100; cat. no. AHO0152; Novex; Thermo Fisher Scientific, Inc.), rabbit anti-nestin (1:100; cat. no. 5413; Sigma-Aldrich; Merck Millipore), rabbit anti-GFAP (1:50; cat. no. ab7260; Abcam), mouse anti-tubulin- $\beta$ III (1:100; cat. no. 7751; Abcam), rabbit anti-S100 (1:100; cat. no. ab868; Abcam) and rabbit anti-C-X-C chemokine receptor 4 (CXCR4; 1:100; cat. no. ab2074; Abcam). Following washing with PBS (cat. no. 10010015; Gibco; Thermo Fisher Scientific), Alexa488-conjugated anti-mouse (1:500; cat. no. A11059; Novex; Thermo Fisher Scientific, Inc.) and Alexa633-conjugated anti-rabbit (1:500; cat. no. A21071; Novex; Thermo Fisher Scientific, Inc.) secondary antibodies were applied for $2 \mathrm{~h}$ at $37^{\circ} \mathrm{C}$. The nuclei were stained with 4',6-diamidino-2-phenylindole (cat. no. D1306; Molecular Probes; Thermo Fisher Scientific, Inc.) and following washing mounted in Mowiol (cat. no. 324590; Sigma-Aldrich; Merck Millipore). Control samples were stained without using primary antibodies and were visualized under a fluorescence microscope.

Rats underwent stereotactic intracranial implantation of C6 rat glioma cells (Narishige, Tokyo, Japan). Rats were anesthetized with an intraperitoneal injection of Zoletil 100 (Virbac, Carros, France) and Rometar (Bioveta, Ivanovice na Hané, Czech Republic) at a 1:4 ratio for $10 \mathrm{mg} / \mathrm{kg}$ body mass. Soft tissues were dissected under sterile conditions, and a burr hole was made with a microdrill (Harvard Bioscience, Inc., Holliston, MA, USA). C6 glioblastoma cells $\left(0.2 \times 10^{6}\right)$ were injected with a Hamilton syringe into caudoputamen area based on the coordinates from the rat brain atlas (18): Anterior-posterior, -1; medial-lateral, 3.0; dorsal-ventral, 4.5; to a depth of $5 \mathrm{~mm}$ and a rate of $3 \mu \mathrm{l} / \mathrm{min}$. Tumor development was monitored using MRI.

Migration of HSCs in vivo. HSCs were first washed with PBS, then twice with DMEM containing 10\% FBS and 1\% penicillin/streptomycin. Subsequently, cells were centrifuged at $800 \mathrm{x} \mathrm{g}$ for $10 \mathrm{~min}$ at $20^{\circ} \mathrm{C}$. The suspension was put through a $10-\mu \mathrm{m}$ nylon filter. Cells were assessed by flow cytometry, following staining with the tracker dyes Vybrant ${ }^{\circledR}$ carboxyfluoresceindiacetatesuccinimidyl ester (CFDA-SE; Molecular Probes; Thermo Fisher Scientific, Inc.; excitation, 488 nm; emission, 492/517 nm) and Cell Tracker ${ }^{\mathrm{TM}}$ Red CMTPX (excitation, $546 \mathrm{~nm}$; emission, 577/602 nm). The central tail vein of rats was catheterized for $1 \mathrm{~min}$, and all animals were injected with labeled HSCs.

To conduct a histological analysis, 7 or 14 days following transplantation of glioma $\mathrm{C} 6$ cells into rat brains, the rats were deeply anesthetized and perfused transaortically by introducing a solution of 4\% PFA. After fixing, the rat skull was opened, the brain was removed and fixed in 4\% PFA. Serial brain sections (20- and $40-\mu \mathrm{m}$ thick) were prepared on a cryostat, and 7- $\mu \mathrm{m}$ thick paraffin sections were prepared on a microtome. The sections were stained with hematoxylin and eosin. The sections were observed under a Axio Scope A1 light microscope (Zeiss GmbH, Jena, Germany) or a Zeiss LSM 710 META confocal microscope (Zeiss $\mathrm{GmbH}$ ), and images were captured using an AxioCam ICc3 digital camera (Zeiss $\mathrm{GmbH}$ ). Cell counting was performed using ImageJ software (version, 1.47; National Institutes of Health, Bethesda, MD, USA).

Statistical analysis. Statistical analysis of data was performed using the GraphPad Prism data analysis software (version 5.01; GraphPad Software, Inc., La Jolla, CA, USA). Data are presented as the mean \pm standard deviation. The Student's $t$-test and Mann Whitney $\mathrm{U}$ tests were used to compare groups. $\mathrm{P}<0.05$ was considered to indicate a statistically significant difference.

\section{Results}

NSCs demonstrated the greatest ability to migrate in vitro and more CSCs results in increased migration. The results 


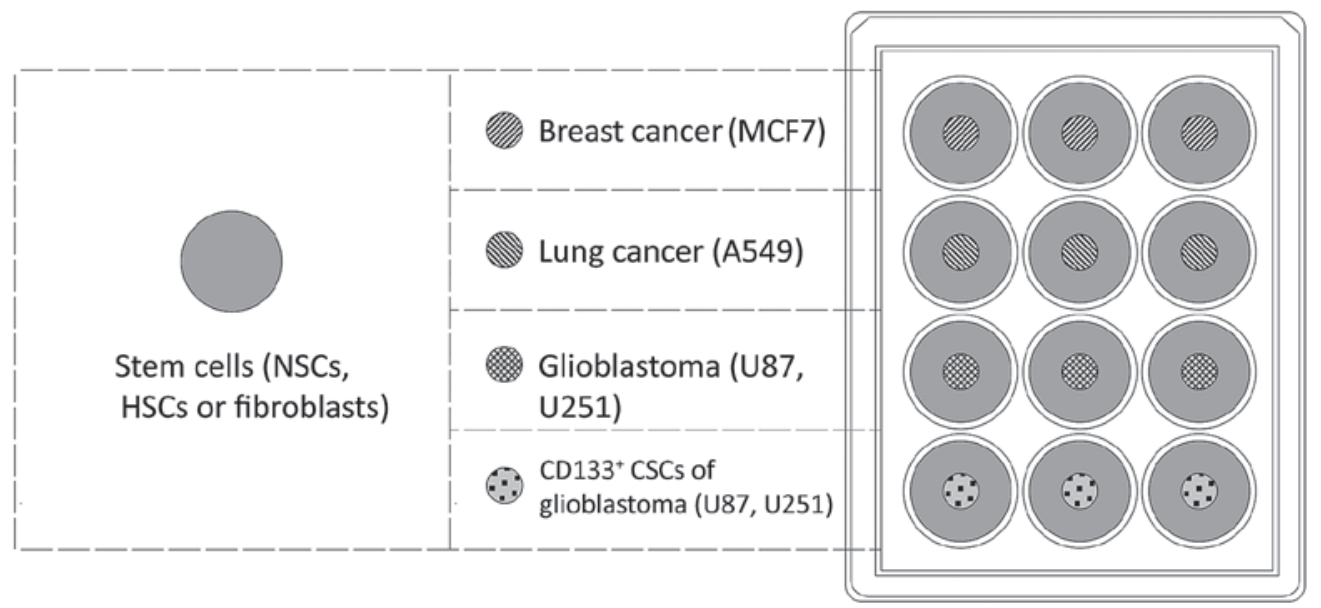

Figure 1. Schematic of the experiment to investigate the targeted migration of tissue-specific stem cells to cancer cells. NSCs, HSCs or fibroblasts were placed into the wells of a 12-well plate, which contained inserts of breast, lung, glioblastoma (all) or glioblastoma (CD133+ cells only). NSCs, neural stem cells; HSCs, hematopoietic stem cells; CD133, cluster of differentiation 133.

of comparative analysis of cell migration activity in mixed cultures are presented in Fig. 2. NSCs migrated to a greater extent than HSCs and fibroblasts, dependent on the type of tumor cells present in the mixed culture. NSCs migrated more actively to the CSCs of two glioblastoma types. Non-separated glioblastoma cells had reduced NSCs migration-inducing ability, and tumor cells of non-neural origin were even less able to induce migration of NSCs.

HSCs had a slightly reduced migration activity to glioblastoma cells compared with NSCs; however, they demonstrated an increased migration rate towards tumor cells of ectodermic origin. Differentiated fibroblasts migrated towards tumor cells; however, at a reduced rate compared with NSCs and HSCs. In general, $\mathrm{CD} 133^{+} \mathrm{CSC}$ derived from U87 and U251 cell lines induced migration to the greatest extent.

It is currently thought that CSCs are responsible for the key properties of glioblastoma, namely treatment resistance and invasive potential. In the present study, the proportion of CSCs in glioblastoma cultures was low. The population of $\mathrm{CD}_{133^{+}}$cells was $1.3 \pm 2.8 \%$ of total U87 cells and $3.4 \pm 2.6 \%$ of total U251 human glioblastoma cells. The direct correlation between the number of CSCs in mixed cultures and the ability to attract stem cells may indicate that that the processes of initiation and maintaining the migration towards the tumor are supported by the subpopulation of stem cells within the tumor.

Notably, the present study revealed a relatively weak ability of mammary cancer and lung cancer cell cultures to attract SCs. Mammary cancer is a hormone-dependent malignant tumor that is surpassed in metastasis and lethality only by lung cancer, the latter being a leading cause of cancer mortality. The decreased ability to attract SCs may be associated with multiple passages of this line in vitro, resulting in the loss of a number of important signaling mechanisms.

Notably, NSCs had the greatest ability to migrate toward tumors of neuroepithelial origin, whereas their migration to tumors of other tissues was reduced compared with HSCs. Migration activity may therefore be greater between cells with a common histogenetic source and, thus, similar transcription and proteome profiles.
HSCs indicate lower numbers of identical proteins, however, show improved migration to $\mathrm{CD} 133^{+}$cells. Following cell lysis, the quantity of common proteins in lysates was as follows: NSCs (sample 1), 2032 $\pm 85 \mu \mathrm{g} / \mathrm{ml}$; U87 line CSCs (sample 2), $2150 \pm 360 \mu \mathrm{g} / \mathrm{ml}$; and HSCs (sample 3), 3198 $\pm 281 \mu \mathrm{g} / \mathrm{ml}$. The processing of LC-MS data by the Mascot Server program identified 1,664 proteins in all samples. Subsequent to processing with Skyline the following levels were detected: Sample 11,447 proteins based on 11,176 peptides (protein molecular weight, 3.53-3,908.10 kDa); sample 2, 1,225 proteins based on 13,674 peptides (protein molecular weight, 4.60-3,908.10 kDa); and sample 3, 842 proteins based on 10,932 peptides (protein molecular weight 5.02-1,017.07 kDa). The dynamic range for identified proteins is 7 orders, which allowed the identification of low-copy-number proteins.

Proteins identified in only one cell type were eliminated from proteome profiles of the compared groups. Thus, 1,659 proteins were divided into comparison group A for NSCs and CSCs (1,052 proteins) and comparison group B for HSCs and CSCs (607 proteins). The results in comparison group A (63.4\% identical proteins) revealed the similarity of the morphofunctional phenotypes of NSCs and CSCs in human glioblastoma; these two cells represent a certain cell type with a specific differentiation and localization in the central nervous system. Comparison group B had only 607 (36.6\%) identical proteins in analyzed proteomes.

The results suggest a close association between glioblastoma CSCs and NSCs, providing an explanation for the increased migration; however, this does not render them a potential treatment tool. The significant differences between CSCs and HSCs proteomes indicate that HSCs are involved in the neoplastic process in the human brain to a much lesser extent; therefore, they have retained their regulation properties. The ability of HSCs to migrate towards CD133 ${ }^{+} \mathrm{U} 87$ and U251 cells means they are a potential treatment tool for glioblastoma CSCs treatment. Therefore, the evaluation of migration potential in vivo was conducted with HSCs only.

HSCs migrate to glioma cells in vivo. Immunofluorescence of C6 glioblastoma cells revealed that $98.8 \pm 13.3 \%$ of cells 


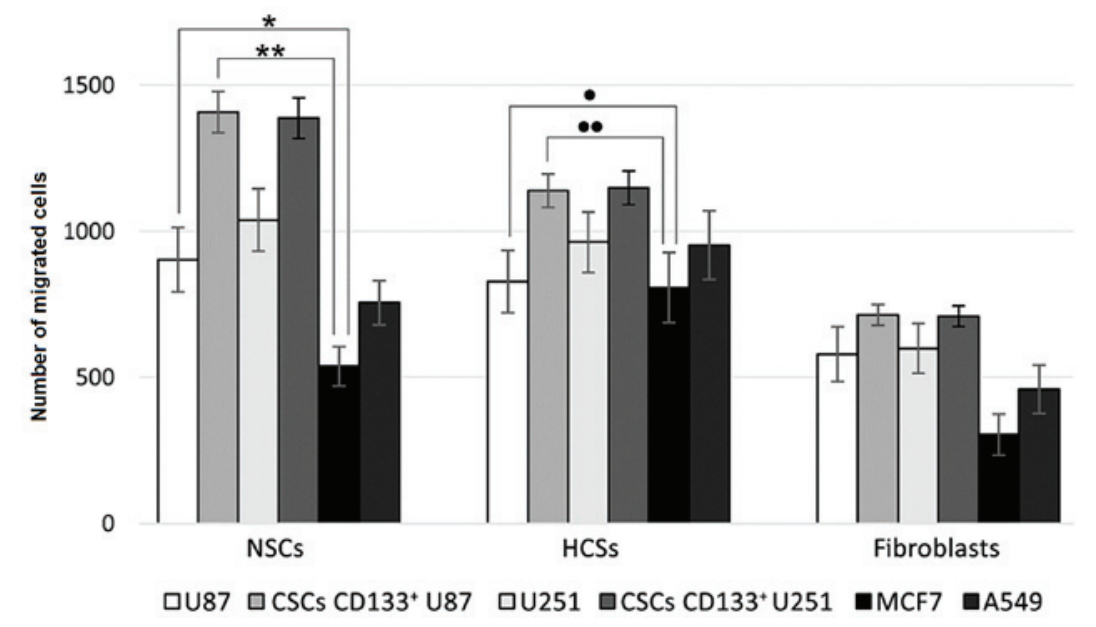

Figure 2. Migration of NSCs, HSCs and fibroblasts towards cancer cells. The number of NSCs, HSCs and fibroblasts that migrated through the culture plate insert towards U87 and U251 human glioblastoma cells and CD133+ cells sorted from these cells, MCF7 human breast cancer cells and A549 human lung cancer cells following $120 \mathrm{~h}$ of co-culture was analyzed. Data are expressed as the mean \pm standard deviation. Mann-Whitney U-test; "P<0.05 vs. U87; ${ }^{* *} \mathrm{P}<0.01$ vs. CSCs CD133+ U87; ${ }^{\circ} \mathrm{P}<0.05$ vs. U87; " $\mathrm{P}<0.01$ vs. CSCs CD133+ U87. NSCs, neural stem cells; HSCs, hematopoietic stem cells; CD133, cluster of differentiation 133.
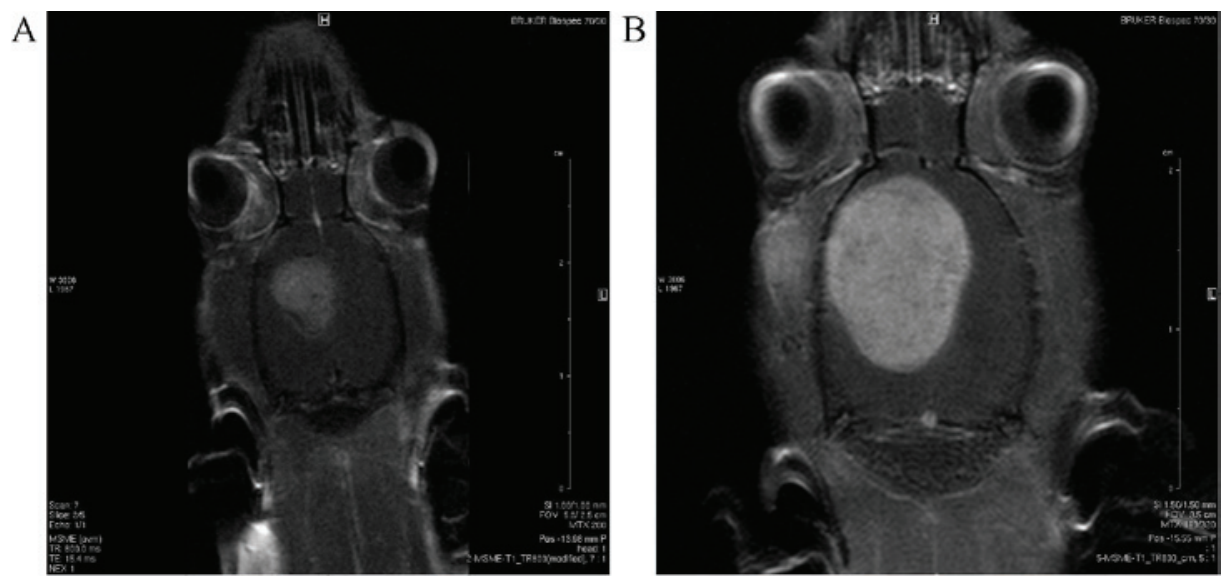

Figure 3. Magnetic resonance images showing tumor development in rat brains at (A) 7 days and (B) 14 days following implantation of tumor cells.

expressed nestin and $82.3 \pm 16.4 \%$ expressed the mutant $\mathrm{p} 53$ protein. A proportion of cells stained positive for CXCR4 (53.7\%), S100 calcium binding protein (9.4\%), GFAP (7.2\%) and $\beta$ III-tubulin (9.3\%). Stereotactic implantation of glioma cells into a rat brain led to rapid tumor development visualized through MRI (Fig. 3).

Histological analysis of the tumor revealed cells of different shapes with varying numbers of nuclei. The tumor tissue contained multiple microvessels, suggesting high-speed metabolism. Along the tumor periphery glioma cells invaded the distrophically altered brain parenchyma. The cells were clustered at a distance from the primary node creating conglomerates that became secondary satellite tumors with a central blood vessel. On observation day 20, tumor cells in neoplastic tissue began to die. Necrosis in the center of the tumor node appeared, at a distance from the feeding blood vessels, demonstrating the inability of the blood supply system to satisfy the requirements of fast growing cells. The tumor cells formed thick node-like clusters around the feeding blood vessel against a background of necrosis (Fig. 4).
Injecting the animals with fluorochrome-labelled HSCs allowed their migration to be tracked in the brain and parenchymal organs. The greatest number of HSCs during the whole observation term was recorded in the brain. At 7 days following HSCs injection fluorescent areas were observed in brain parenchyma in close proximity to the tumor; the size of fluorescent objects was equal to the size of transplanted cells (10-20 $\mu \mathrm{m})$. Upon reaching the neoplastic node, HSCs clustered along the border with normal tissue ( $>100$ cells visible) and by means of diffusion penetrated the tumor tissue. HSCs were clearly visible along the tumor borders and in the center of the neoplasm 14 days following injection (Fig. 5).

Fluorescence of CFDA-SE stained cells lasted longer than that of CMTPX. At seven days following injection, in the brain of the control group animals (without injected tumor), the majority of transplanted cells were located close to or inside the parenchymal vessel walls or in brain parenchyma where they exhibited a long-lasting fluorescence with spectrum characteristics distinct from the autofluorescence of brain tissue (Fig. 6).

Parenchymal organs of experimental group animals revealed the singular fluorescent objects of the required size in 

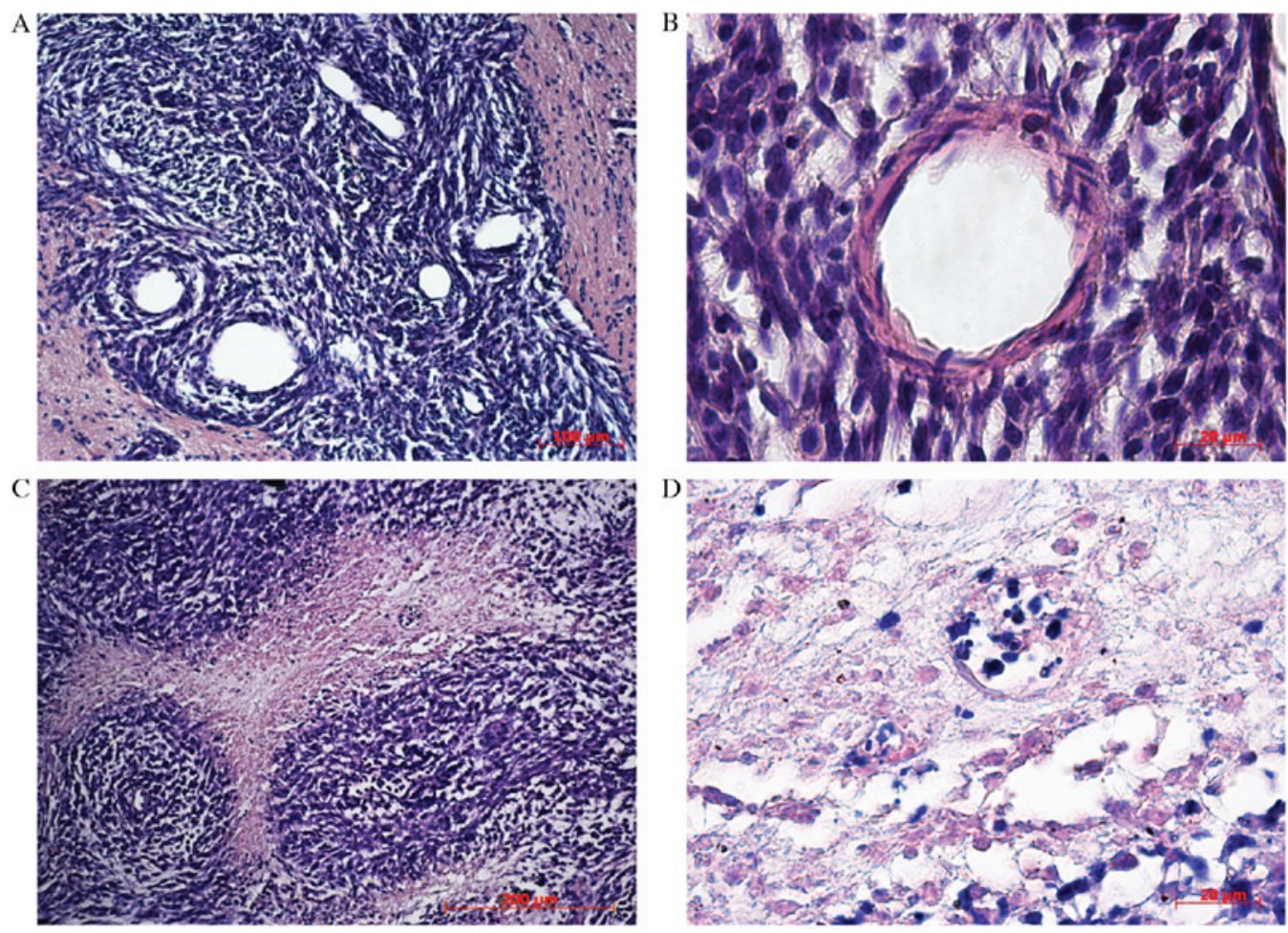

Figure 4. Hematoxylin and eosin staining of rat brain tumors, 20 days after implantation of tumor cells. (A) Tumor tissue with newly formed blood vessels, (B) Blood vessel development among satellite tumor cells. (C) Angiocentric clusters of tumor cells. (D) Necrotic areas in tumor tissue, 30 days after implantation of tumor cells.
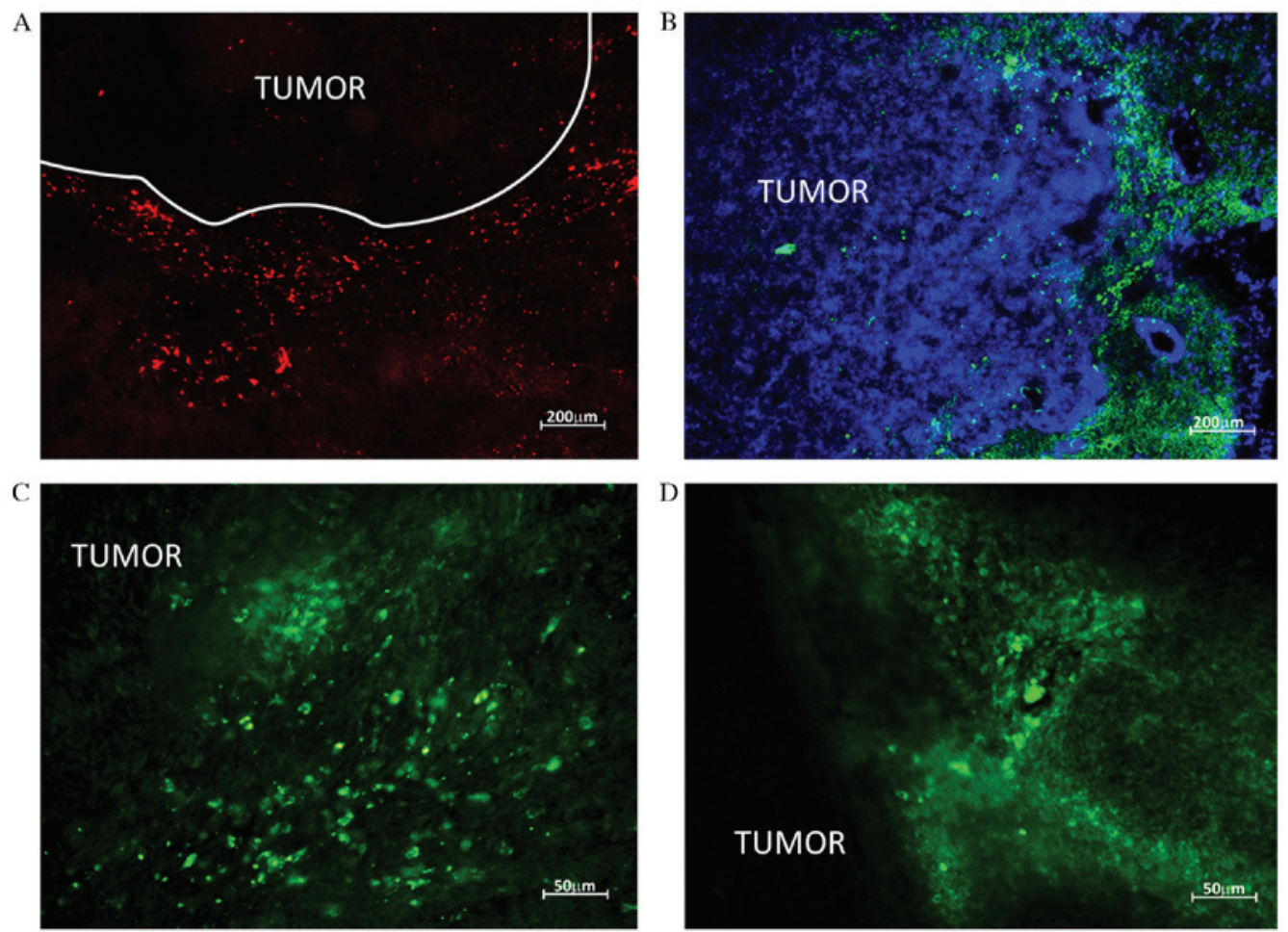

Figure 5. HSC migration to rat brain tumors. HSCs labeled with red CMTPX and green carboxyfluoresceindiacetatesuccinimidyl ester were detected by confocal microscopy in rat brain glioblastomas following intravenous injection (A and B) HSCs are localized along the borders of neoplastic node (C and D) HSC migration to the tumor parenchyma. HSCs, hematopoietic stem cells.

lung, spleen and bone marrow tissues 7 days following injection. On day 14 there were no signs of transplanted cells in rats of control and experimental groups. The majority of analyzed organs had autofluorescent cells, the intensity of which was 
Table I. Secreted proteins present in U87 human glioblastoma cancer stem cells.

NSI, $\%$ Protein

0.018017

0.017455

0.230439

0.291456

0.701277

0.023723

0.059753

0.009112

0.167202

0.012532

0.006565

0.084246

0.000635

0.60557

0.01018

0.157602

0.029513

0.083528

0.103943

0.182445

0.015039

0.259942

0.007125

0.084381

0.054239

0.004402
CD59 molecule, complement regulatory protein

Niemann-Pick disease, type C2

Actinin, alpha 1

Actinin, alpha 4

Annexin A2 pseudogene 3; annexin A2; annexin A2 pseudogene 1

Calmodulin 3 (phosphorylase kinase, delta); calmodulin 2 (phosphorylase kinase, delta);

calmodulin 1 (phosphorylase kinase, delta)

Calumenin

Cathepsin B

Cathepsin D

Collagen, type VI, alpha 3

Dermcidin

Gelsolin (amyloidosis, Finnish type)

Granulin

Heat shock $60 \mathrm{kDa}$ protein 1 (chaperonin) pseudogene 5; heat shock $60 \mathrm{kDa}$ protein 1 (chaperonin) pseudogene 6; heat shock $60 \mathrm{kDa}$ protein 1 (chaperonin) pseudogene 1; heat shock $60 \mathrm{kDa}$ protein 1 (chaperonin) pseudogene 4; heat shock $60 \mathrm{kDa}$ protein 1 (chaperonin)

High density lipoprotein binding protein

Macrophage migration inhibitory factor (glycosylation-inhibiting factor)

Peroxiredoxin 4

Phosphatidylethanolamine binding protein 1

Plasminogen

Prosaposin

Reticulon 3

Ribonuclease/angiogenin inhibitor 1

Serpinpeptidase inhibitor, clade E (nexin, plasminogen activator inhibitor type 1), member 2

Superoxide dismutase 1, soluble

Tyrosyl-tRNA synthetase

Zinc finger protein 91 homolog (mouse); ZFP91-CNTF readthrough transcript; ciliary neurotrophic factor

NSI, normalized signal intensity.
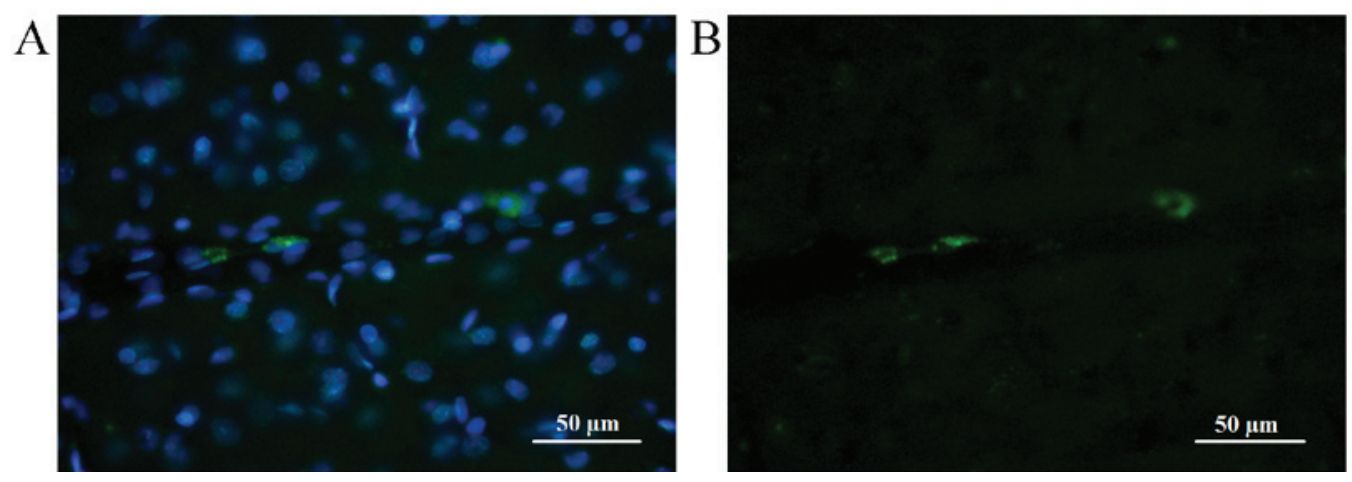

Figure 6. Representative fluorescence images demonstrating the migration of hematopoietic stem cells stained with (A) DAPI and (B) carboxyfluoresceindiacetatesuccinimidyl ester in rat brain tissues at 5 days.

evaluated based on the same parameters for the control and the experimental group.

Lung, spleen and liver tissues revealed weak fluorescence; however, the spectrum was distinct from the fluorescence of the injected cells. In kidneys this signal was discovered in tubule epithelial cells, while in lungs it was present in a small group of alveolocytes and cells of interalveolar septum with an oblong or rounded shape. If an animal had inflammation 
of the lung parenchyma, the number of autofluorescent cells in that area was increased, in control and experimental group animals (data not shown).

\section{Discussion}

Transplantation of stem cells is a primary clinical method of treating malignant tumors due to the strong ability of transplanted cells to migrate to the damaged area. Currently it is the sole method that may radically improve patient prognosis in the case of hemoblastosis. A crucial stage in treatment of oncohematologic diseases and certain other cancer types is radiation and high-dosage chemotherapy. By eliminating hematopoietic cells these strategies destroy their local microsurroundings in bone marrow, while the transplanted stem cells will find their way to the damaged area, populate and remodel it by creating new conditions of local microenvironment $(19,20)$.

Targeted migration of SCs to the damaged area has been considered only in terms of its reparative function, until recently. This process is induced by numerous factors released in the damaged area binding to the corresponding stem cell receptors. The role of stromal cell-derived factor interacting with CXCR4 on SCs is defined as is the role of stem cell factor, hepatocyte growth factor, vascular endothelial growth factor (VEGF), monocyte chemotactic protein, proteins inhibiting microphages migration and $>80$ other factors produced by the damaged tissues $(21,22)$.

However, stem cell migration to the neoplastic nidus is not only a reparative phenomenon. The results of the present study demonstrate that tumor cells are a primary source of signals activating the targeted migration of stem cells. The ability of neuroepitheial tumors to produce tenastin, fibronectin, laminin and collagen of various types has been demonstrated; the production of these proteins by the damaged tissues has been associated with the targeted migration of SCs. In addition, an important characteristic of glioblastoma is hypoxia, which maintains cells in a non-differentiated state for an extended period and triggers the expression of more $>100$ genes inducing SCs migration (23).

In the present study, CSCs had the greatest stability to attract SCs. Numerous cytokines are released by CSCs, including chitinase 3-like protein 1, a disintegrin and metalloproteinase (ADAM) 9, ADAM10, cathepsins B and L1, osteopontin, semaphoring 7A and other inducers of targeted migration and stem cell homing $(24,25)$. In the present study, 33 released proteins were identified in the CSC proteome that may potentially influence stem cell migration (as presented in Table I).

Notably, NSCs were markedly more active in relation to glioblastoma CSCs. During tumor development in the nervous tissue NSCs and CSCs develop complex interactions. Glioblastoma development inhibits NSC proliferation in germinal brain areas in older experimental animals (26). However, NSCs may be a source of cells recruited by the tumor for proliferation and metabolism. NSCs and glioblastoma CSCs have numerous similar morphological and biochemical properties; they actively proliferate in vitro and create neurospheres (gliomaspheres), and they may differentiate following the introduction of various factors, including VEGF, nerve growth factor and bone morphogenetic protein into the medium. Nestin is the most important marker of NSCs, and this marker was present in the majority of C6 glioblastoma cells that were used in the present study. NSC descendants are neural progenitor cells that are constantly migrating from subventricular zone; this partially accounts for their high mobility in the present study $(27,28)$.

NSCs may transform into CSCs due to the environmental conditions of the tumor. The high level of similarity $(63.5 \%)$ between NSCs and CSCs demonstrated in the present study supports this hypothesis. By contrast, HSCs with a decreased mobility to CSCs in mixed cultures have fewer proteins expressed by CSCs, suggesting that this cell type is less prone to neoplastic transformation in neural tumors. HSCs may therefore be a potential tool for developing technologies aimed at controlling the activity of glioblastoma CSCs.

The standard method for evaluating the migration of exogenous cells in experimental animals is fluorescence laser microscopy (29); however, implanted SCs in animal organs do not always demonstrate definite results. HSCs fluorescence in parenchymal organs has been described for rats injected with Lewis, Ehrlich and Fisher adenocarcinoma along with certain other models; however, fluorescent cells were identified in the tumor tissue. Clusters of transplanted cells in tumor-carrying organism are typically observed in lung, spleen and bone marrow. This fact is frequently explained by the small quantity of injected cells and the obstacles produced by autofluorescence of the examined tissues, or the inadequacy of the selected cell type and animal species for the experiment (30).

The targeted migration of SCs to the neoplastic tumor has been demonstrated using experimental glioblastoma models for hematopoietic, neural, fetal and embryonic SCs $(31,32)$. The ability to attract SCs may be a key glioblastoma property. This may be associated with the high concentration of CSCs in the population of cancer cells.

Interaction of normal and cancer SCs in the neoplasia area creates certain conditions resulting in suppression of tumor proliferation, angiogenesis and metastasis, stimulation of inflammation and initiation of apoptosis. Certain underlying mechanisms of this interaction have been described, including intensification of specific cytokines production, tumor cell cycle arrest in $\mathrm{G}_{1}$ phase, proapoptotic modification of SCs increasing the efficiency of cytoplasmic protein exchange and the by-stander effect and molecular adhesion phenomenon (33-35).

The phenomenon of molecular adhesion was first described by Aboody et al (36) in 2000. It is based on the SCs unique ability to follow the tumor cell into the brain parenchyma using its cytokine trail, reach and adhere to it. Our laboratory has described the mechanism underlying intercellular communication between stem and tumor cells via exosomes, enabling active cytoplasmic protein exchange that suppresses tumor cell proliferation (37). It can be assumed that modifying the proteome profile of HSCs may facilitate the generation of cell systems that can trigger targeted apoptosis in neoplastic stem cells.

In conclusion, the results of the present study demonstrate that CSCs demonstrate the greatest ability to attract normal SCs, out of all tumor cells assessed. The differences in cell proteomes suggest HSCs as a potential tool for interacting with glioblastoma CSCs. Following the injection of 
experimental animals with glioblastoma, HSCs migrated to the brain hemisphere containing the tumor and penetrated the neoplastic tissue. Further research regarding the application of hematopoietic stem cells in the treatment of malignant tumors of the central nervous system is required, however, the results of the present study form the basis for the production of novel antitumor therapies.

\section{Acknowledgements}

The present study was conducted with financial support from the Russian Science Foundation (project no. 14-15-00084).

\section{References}

1. Omuro A and DeAngelis LM: Glioblastoma and other malignant gliomas: A clinical review. JAMA 310: 1842-1850, 2013.

2. Stupp R and Hegi ME: Brain cancer in 2012: Molecular characterization leads the way. Nat Rev Clin Oncol 10: 69-70, 2013.

3. Stupp R and Weber DC: The role of radio- and chemotherapy in glioblastoma. Onkologie 28: 315-317, 2005.

4. Soltanian S and Matin MM: Cancer stem cells and cancer therapy. Tumour Biol 32: 425-440, 2011.

5. Tabatabai G and Weller M: Glioblastoma stem cells. Cell Tissue Res 343: 459-465, 2011.

6. Taal W, Bromberg JE and van den Bent MJ: Chemotherapy in glioma. CNS Oncol 4: 179-192, 2015.

7. Lathia JD, Mack SC, Mulkearns-Hubert EE, Valentim CL and Rich JN: Cancer stem cells in glioblastoma. Genes Dev 29: 1203-1217, 2015.

8. Zaridze DG: Carcinogenesis. Medicine (ed. Zaridze, D.G.) 1-567, 2004.

9. Hide T, Makino K, Nakamura H, Yano S, Anai S, Takezaki T, Kuroda J, Shinojima N, Ueda Y and Kuratsu J: New treatment strategies to eradicate cancer stem cells and niches in glioblastoma. Neurol Med Chir (Tokyo) 53: 764-772, 2013.

10. Duesberg P, Mandrioli D, McCormack A and Nicholson JM: Is carcinogenesis a form of speciation? Cell Cycle 10: 2100-2014, 2011

11. Pecchia I, Dini V, Ricci-Vitiani L, Biffoni M, Balduzzi M, Fratini E, Belli M, Campa A, Esposito G, Cirrone G et al: Glioblastoma stem cells: Radiobiological response to ionising radiations of different qualities. Radiat Prot Dosimetry 166: 374-378, 2015.

12. Bryukhovetskiy IS, Mischenko PV, Tolok EV, Zaitcev SV, Khotimchenko YS and Bryukhovetskiy AS: Directional migration of adult hematopoietic progenitors to C6 glioma in vitro. Oncol Lett 9: 1839-1844, 2015.

13. Bryukhovetskiy I, Bryukhovetsky A, Khotimchenko Y, Mischenko P, Tolok E and Khotimchenko R: Combination of the multipotent mesenchymal stromal cell transplantation with administration of temozolomide increases survival of rats with experimental glioblastoma. Mol Med Rep 12: 2828-2834, 2015.

14. Studeny M, Marini FC, Dembinski JL, Zompetta C, Cabreira-Hansen M, Bekele BN, Champlin RE and Andreeff M: Mesenchymal stem cells: Potential precursors for tumour stroma and targeted-delivery vehicles for anticancer agents. J Natl Cancer Inst 96:1593-1603, 2004

15. Mooney R, Roma L, Zhao D, Van Haute D, Garcia E, Kim SU, Annala AJ, Aboody KS and Berlin JM: Neural stem cell-mediated intratumoural delivery of gold nanorods improves photothermal therapy. ACS Nano 8: 12450-12460, 2014.

16. Kanojia D, Balyasnikova IV, Morshed RA, Frank RT, Yu D, Zhang L, Spencer DA, Kim JW, Han Y, Yu D et al: Neural stem cells secreting anti-HER2 antibody improve survival in a preclinical model of HER2 overexpressing breast cancer brain metastases. Stem Cells 33: 2985-2994, 2015.

17. Pittenger MF: Mesenchymal stem cells from adult bone marrow. Methods Mol Biol 449: 27-44, 2008.

18. Paxinos G and Watson C: The Rat Brain in Stereotaxic Coordinates. 6th edition. Academic Press, Cambridge, MA, pp1-456, 2007.
19. Shipounova IN, Petinati NA, Bigildeev AE, Zezina EA, Drize NI, Kuzmina LA, Parovichnikova EN and Savchenko VG: Analysis of results of acute graft-versus-host disease prophylaxis with donor multipotent mesenchymal stromal cells in patients with hemoblastoses after allogeneic bone marrow transplantation. Biochemistry (Mosc) 79: 1363-1370, 2014.

20. Amson R, Karp JE and Telerman A: Lessons from tumour reversion for cancer treatment. Curr Opin Oncol 25: 59- 65, 2013.

21. Naaldijk Y, Johnson AA, Ishaka S, Meiseld HJ, Hohausd C and Stolzingb A: Migrational changes of mesenchymal stem cells in response to cytokines, growth factors, hypoxia and aging. Exp Cell Res 338: 97-104, 2015.

22. Bryukhovetskiy IS, Bryukhovetskiy AS, Mischenko PV and Khotimchenko YS: Role of systemic migration mechanisms and stem cell homing in the development of malignant tumours of the central nervous system and creating new methods of antitumour therapy. Russian Biotherapeutic Journal 4: 3-12, 2013 (In Russian).

23. Herrera-Perez M, Voytik-Harbin SL and Rickus JL: Extracellular matrix properties regulate the migratory response of glioblastoma stem cells in three-dimensional culture. Tissue Eng Part A 21: 2572-2582, 2015.

24. Sangar V, Funk CC, Kusebauch U, Campbell DS, Moritz RL and Price ND: Quantitative proteomic analysis reveals effects of epidermal growth factor receptor (EGFR) on invasion-promoting proteins secreted by glioblastoma cells. Mol Cell Proteomics 13: 2618-2631, 2014.

25. Formolo CA, Williams R, Gordish-Dressman H, MacDonald TJ, Lee NH and Hathout Y: Secretome signature of invasive glioblastoma multiforme. J Proteome Res 10: 3149-3159, 2011.

26. Walzlein JH, Synowitz M, Engels B, Markovic DS, Gabrusiewicz K, Nikolaev E, Yoshikawa K, Kaminska B, Kempermann G, Uckert W et al: The antitumourigenic response of neural precursors depends on subventricular proliferation and age. Stem Cells 26: 2945- 2954, 2008.

27. Miska J and Lesniak MS: Neural stem cell carriers for the treatment of glioblastoma multiforme. EBioMedicine 2: 774-775, 2015.

28. Neradil J and Veselska R: Nestin as a marker of cancer stem cells. Cancer Sci 106: 803-811, 2015.

29. Furia L, Pelicci P and Faretta M: Confocal microscopy for high-resolution and high-content analysis of the cell cycle. Curr Protoc Cytom 70: 7.42.1-7.42.14, 2014

30. Motaln H and Turnsek TL: Cytokines play a key role in communication between mesenchymal stem cells and brain cancer cells. Protein Pept Lett 22: 322-331, 2015.

31. Kidd S, Spaeth E, Dembinski JL, Dietrich M, Watson K, Klopp A, Battula VL, Weil M, Andreeff M and Marini FC: Direct evidence of mesenchymal stem cell tropism for tumour and wounding microenvironments using in vivo bioluminescent imaging. Stem Cells 27: 2614-2623, 2009.

32. Moore XL, Lu J, Sun L, Zhu CJ, Tan P and Wong MC: Endothelial progenitor cells' 'homing' specificity to brain tumours. Gene Ther 11: 811-818, 2004.

33. Aboody KS, Najbauer J, Metz MZ, D'Apuzzo M, Gutova M, Annala AJ, Synold TW, Couture LA, Blanchard S, Moats RA et al: Neural stem cell-mediated enzyme/prodrug therapy for glioma: Preclinical studies. Sci Transl Med 5: 184ra59, 2013.

34. Liu Y, Kobayashi A, Maeda T, Fu Q, Oikawa M, Yang G, Konishi T, Uchihori Y, Hei TK and Wang Y: Target irradiation induced bystander effects between stem-like and non-stem-like cancer cells. Mutat Res 773: 43-47, 2015.

35. Chan JK and Lam PY: Human mesenchymal stem cells and their paracrine factors for the treatment of brain tumours. Cancer Gene Ther 20: 539-543, 2013.

36. Aboody KS, Brown A, Rainov NG, Bower KA, Liu S, Yang W, Small JE, Herrlinger U, Ourednik V, Black PM et al: Neural stem cells display extensive tropism for pathology in adult brain: Evidence from intracranial gliomas. Proc Natl Acad Sci USA 97: 12846-12851, 2000.

37. Bryukhovetskiy IS, Mischenko PV, Tolok EV, Khotimchenko YS, Zaitcev SV and Bryukhovetskiy AS: Hematopoietic stem cells with induced apoptosis effectively inhibit glioma cell growth in vitro, but started new mechanism of tumour stem cells. Genes and Cells 9: 70-75, 2014. 